\title{
Periodontal Disease in the COVID-19 Era: Potential Reservoir and Increased Risk for SARS-CoV-2
}

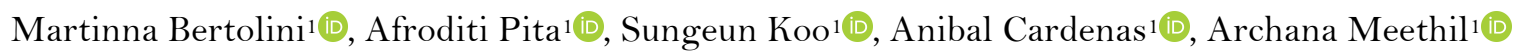

${ }^{1}$ Department of Oral Health and Diagnostic Sciences, School of Dental Medicine, University of Connecticut, Farmington, CT, USA.

Author to whom correspondence should be addressed: Martinna Bertolini, Department of Oral Health and Diagnostic Sciences, School of Dental Medicine, University of Connecticut, 263 Farmington Ave, Farmington, CT, USA. Phone: +8609706391. E-mail: martinnabertolini@gmail.com

Academic Editor: Yuri Wanderley Cavalcanti

Received: 16 June 2020 / Review: 28 June 2020 / Accepted: 06 July 2020

How to cite this article: Bertolini M, Pita A, Koo S, Cardenas A, Meethil A. Periodontal disease in the COVID-19 era: potential reservoir and increased risk for SARS-CoV-2. Pesqui Bras Odontopediatria Clín Integr. 2020; 20(supp1):e0134. https://doi.org/10.1590/pboci.2020.162

\begin{abstract}
Since December 2019, an outbreak of Coronavirus Disease 2019 (COVID-19) caused by severe acute respiratory syndrome coronavirus 2 (SARS-CoV-2) emerged in China and is now becoming a global Pandemic, with over 10.5 million cases worldwide. Angiotensin-converting enzyme-2 (ACE-2) has been considered the main receptor for the SARS-CoV-2 entry into human cells, and they are known to be present not only in lungs (therefore the common viral pneumonia) but also in nasopharyngeal mucosa, salivary cells and oral epithelial cells. Moreover, there seems to be recent evidence showing that the crevicular fluid on the periodontal pockets of patients presenting periodontitis could harbor SARS-CoV-2 and act as a potential reservoir for increased viral load in the oral cavity of COVID-positive patients. Additionally, sites with active periodontal disease might contribute for virus binding and tissue infection due to elevated expression of furin and cathepsin L proteases, which play a major role in enabling the SARS-CoV-2 to bind ACE-2 receptors and facilitating endosomal fusion in the host cells. Taken together this news and views article highlight possible virus reservoirs in COVID-positive patients, as well as increased risk for infection in patients with active periodontal disease, further proposing potential targets for antiviral intervention on SARS-CoV-2 infection.
\end{abstract}

Keywords: Coronavirus Infections; SARS Virus; Periodontics; Periodontal Diseases. 


\section{Introduction}

In December of 2019, series of pneumonia cases were reported in China [1] associated with a novel coronavirus, which has been identified as "Severe Acute Respiratory Syndrome Coronavirus 2" (SARS-CoV-2), that is phylogenetically related to the class of viruses that cause acute respiratory syndrome, including SARSCOV and MERS-COV. Later, in January 2020, the disease was named "COVID-19" ("COVI" - coronavirus, "D" - disease, and 19 represents 2019 when the virus was first identified in China).

Current epidemiologic data from WHO [1] indicate that person-to-person contact led to a total of more than 10.5 million cases in at least 21 countries by January 2020 [2]. And currently, Brazil accounts for almost $11 \%$ of all COVID-positive cases worldwide. While investigations are still underway worldwide to better understand transmission dynamics and the spectrum of clinical illness, new guidelines are proposed daily with measures on how to better manage possible infected patients and reduce spreading.

As we enter the second quarter of the COVID-19 pandemic, with dental practices reopening for patient care, two important questions were recently raised in the periodontal research community: 1) Are periodontal pockets a potential reservoir for SARS-CoV-2? [3]; 2) Can periodontal disease increase the risk of COVID-19? [4]. We think these two questions are worth it the discussion, as they might help to re-shape the future guidelines for periodontal therapy on periodontitis patients positive for COVID-19.

\section{Periodontal Disease and Viruses}

Periodontal disease is a chronic multifactorial inflammatory disease characterized by progressive destruction of the tooth-supporting apparatus. Though the bacterial biofilm accumulation and maturation initiates gingival inflammation, progression of periodontal disease occurs consequent to the host response and dysbiotic changes in the microbiome. Dysbiosis may be modulated by inflammatory and tissue breakdown products, which selectively enrich certain bacterial species and by anti-inflammatory products released at the site of inflammation [5].

Since the mid-1990s, viruses have been described as pathogens related to periodontal disease, with Epstein-Barr virus type 1 (EBV-1) being detected in $43 \%$ of periodontal sites and in only $18 \%$ of healthy sites [6]. Later, Herpes simplex virus and Human Cytomegalovirus have been described as positive in periodontal pockets of $26-78 \%$ and $42-58 \%$, respectively, of patients with periodontal disease, showing different virus families be found in unique rates across the population [7].

Further corroborating this, a recent shot-gun DNA sequencing study of subgingival plaque collected from healthy and periodontal disease patients showed that even though bacteria were the most abundant component of the subgingival plaque, with over $95 \%$ of the reads, viruses were also present in these complex communities associated with bacterial biofilm complexes [8].

\section{Are Periodontal Pockets a Potential Reservoir for SARS-CoV-2?}

This hypothesis was raised by Badran et al. [3], based on the idea that periodontal pockets could be a favorable environment for virus replication and survival and could, therefore, be an additional focus of infection in COVID-positive patients.

The initial viral infection of periodontal tissues could start either from direct infection of coming from the mouth or from cells basement membrane by bloodstream or infected immune cells [9]. The continuous inflammatory response present in affected sites of periodontal disease could bring mononuclear cells infected 
by SARS-CoV-2 [10]. Thus, it is reasonable to think that the crevicular fluid on the periodontal pocket could harbor virus arriving from infected mononuclear cells and further mix with patient's saliva.

Angiotensin-converting enzyme-2 (ACE-2) has been considered the main receptor for the SARS-CoV2 entry into human cells, and they are present not only in lungs (therefore the common viral pneumonia), but also in nasopharyngeal mucosa, salivary gland and oral epithelial cells [11]. This results in high viral load in the oral cavity (saliva and crevicular fluid), which has been tackled in dental practices by antimicrobial prerinses composed by povidone-iodine has been showing promising results in terms of viral killing [12].

Although this has not been experimentally tested yet, it seems plausible that periodontal pockets need to be tested as potential reservoirs for SARS-CoV-2, as they present interactions with the oral cavity and bloodstream via capillary complexes. This hypothesis could be further extrapolated to the peri-implant environment, as increased inflammation is also found around implants and increased EBV prevalence has also been described in peri-implant sites when compared to healthy sites [13].

\section{Does Periodontal Disease Increase the Risk of COVID 19?}

This hypothesis was raised by Balaji et al. [4], based on the fact that the patients presenting periodontal disease exhibit high levels of osteopontin in the gingival crevicular fluid from sites with periodontal destruction [14], and its downstream products play a major role in enabling the SARS-CoV-2 to infect the host cells.

Osteopontin is a noncollagenous, calcium-binding, glycosylated phosphoprotein, commonly found in the mineralized phase of bone matrix, which is mainly synthesized by pre-osteoblasts, osteoblasts and osteoclastic cells and has been shown to be elevated in periodontitis [15]. High osteopontin levels induces NF$\kappa \mathrm{B}$ activation, which then increases furin expression [16]. An inflammatory response (interleukin - IL-6) via gingival fibroblasts will also lead to increased expression of Cathepsin L, a cysteine protease [17].

Both, furin and cathepsin L play a major role in enabling the SARS-CoV-2 to infect the host cells by cleaving $\mathrm{S}$ glycoprotein of the SARS-CoV-2 into $\mathrm{S} 1$ and $\mathrm{S} 2$ subunits by furin, allowing $\mathrm{S} 1$ subunit attaches itself to the ACE2 receptors present in the host cells. Finally, endosomal fusion is mediated by cathepsin B/L, allowing cell fusion and infection [18].

Unravelling which cellular factors are used by SARS-CoV-2 for cell entry might provide insights into viral transmission and reveal therapeutic targets. Recently, Hoffmann et al. [18] demonstrated a protease inhibitor (TMPRSS2, approved for clinical use) was able to block the virus entry on the host cells. Their results reveal important commonalities between SARS-CoV-2 and SARS-CoV infection and identify a potential target for antiviral intervention.

\section{Final Considerations}

In order to tackle the COVID-19 pandemic efficiently, it is crucial to reduce the spread of the infection by not only carrying out extraordinary prevention and safety measures, but also identifying possible virus reservoirs in COVID-positive patients, as well as identify potential targets for antiviral intervention on SARSCoV-2 infection.

This new and views of two recent publications in the periodontal field highlight that periodontal therapy could be considered a parameter of care in the global clinical management of COVID-positive patients, aiming the reduction of viral reservoir in the periodontal pockets. Active periodontal treatment could decrease the expression of furin and cathepsin L, reducing the ability of SARS-CoV-2 to infect the host cells. 


\section{Authors' Contributions}

MB (D) 0000-0003-3619-6618 Conceptualization, Investigation, Writing - Original Draft and Supervision.

AP (D) 0000-0002-8233-1828 Investigation, Data Curation, Writing - Review and Editing.

SK (D) 0000-0002-1469-0749 Investigation, Data Curation, Writing - Review and Editing.

AC (D) 0000-0003-0933-0092 Investigation, Data Curation, Writing - Review and Editing.

AM (D) 0000-0002-1952-0781 Conceptualization, Investigation, Writing - Original Draft and Project Administration. All authors declare that they contributed to critical review of intellectual content and approval of the final version to be published.

\section{Financial Support}

None.

\section{Conflict of Interest}

The authors declare no conflicts of interest.

\section{References}

[1] World Health Organization. Pneumonia of unknown cause - China. Available from: https://www.who.int/csr/don/05-january-2020-pneumonia-of-unkown-cause-china/en/. [Accessed on June 07 , 2020].

[2] Chan JFW, Yuan S, Kok KH, Kai-Wang K, Chu H, Yang J, et al. A familial cluster of pneumonia associated with the 2019 novel coronavirus indicating person-to-person transmission: a study of a family cluster. Lancet 2020; 395(10223):514-23. https://doi.org/10.1016/S0140-6736(20)30154-9

[3] Badran Z, Gaudin A, Struillou X, Amador G, Soueidan A. Periodontal pockets: a potential reservoir for SARS-CoV-2? Med Hypotheses 2020; 143:109907. https://doi.org/10.1016/j.mehy.2020.109907

[4] Madapusi Balaji T, Varadarajan S, Rao USV, Raj AT, Patil S, Arakeri G, et al. Oral cancer and periodontal disease increase the risk of COVID 19? A mechanism mediated through furin and cathepsin overexpression. Med Hypotheses 2020; 144:109936. https://doi.org/10.1016/j.mehy.2020.109936

[5] Papapanou PN, Sanz M, Buduneli N, Dietrich T, Feres M, Fine DH, et al. Periodontitis: Consensus report of workgroup 2 of the 2017 World Workshop on the Classification of Periodontal and Peri-Implant Diseases and Conditions. J Periodontol 2018; 89(Suppl 1):S173-S182. https://doi.org/10.1002/JPER.17-0721

[6] Contreras A, Slots J. Herpesviruses in human periodontal disease. J Periodontal Res 2000; 35(1):3-16. https://doi.org/10.1034/j.1600-0765.2000.035001003.x

[7] Cappuyns I, Gugerli P, Mombelli A. Viruses in periodontal disease - a review. Oral Dis 2005; 11(4):219-29. https://doi.org/10.1111/j.1601-0825.2005.01123.x

[8] Dabdoub SM, Ganesan SM, Kumar PS. Comparative metagenomics reveals taxonomically idiosyncratic yet functionally congruent communities in periodontitis. Sci Rep 2016; 6:38993. https://doi.org/10.1038/srep38993

[9] Miller CS. Viruses: are they really culprits for periodontal disease? a critical review?. J Investig Clin Dent 2014; 5(3):243. https://doi.org/10.1111/jicd.12114

[10] Li L, Wo J, Shao J, Zhu H, Wu N, Li M, et al. SARS-coronavirus replicates in mononuclear cells of peripheral blood (PBMCs) from SARS patients. J Clin Virol 2003; 28(3):239-44. https://doi.org/10.1016/s 1386-6532(03)00195-1

[11] Chao Wu MZ. Single-cell RNA expression profiling shows that ACE2, the putative receptor of COVID-2019, has significant expression in nasal and mouth tissue, and is co-expressed with TMPRSS 2 and not co-expressed with SLC6A19 in the tissues. PREPRINT (Version 1). Available from: https://www.researchsquare.com/article/rs16992/v1. [Accessed on June 07, 2020].

[12] Parhar HS, Tasche K, Brody RM, Weinstein GS, O'Malley Jr BW, Shanti RM, et al. Topical preparations to reduce SARS-CoV-2 aerosolization in head and neck mucosal surgery. Head Neck 2020; 42(6):1268-72. https://doi.org/10.1002/hed.26200

[13] Brown T, Young L, Lamont TJ. Do viruses play a role in peri-implantitis?. Evid Based Dent 2020; $21(1): 8-9$. https://doi.org/10.1038/s41432-020-0072-z

[14] Sharma CG, Pradeep AR. Plasma and crevicular fluid osteopontin levels in periodontal health and disease. J Periodontal Res 2007; 42(5):450-5. https://doi.org/10.1111/j.1600-0765.2007.00968.x

[15] Yongchaitrakul T, Manokawinchoke J, Pavasant P. Osteoprotegerin induces osteopontin via syndecan-1 and phosphoinositol 3-kinase/Akt in human periodontal ligament cells. J Periodontal Res 2009; 44(6):776-83. https://doi.org/10.1111/j.1600-0765.2008.01190.x

[16] Kumar V, Behera R, Lohite K, Karnik S, Kundu GC. p38 kinase is crucial for osteopontin-induced furin expression that supports cervical cancer progression. Cancer Res 2010; 70(24):10381-391. https://doi.org/10.1158/00085472.CAN-10-1470 
[17] Yamaguchi T, Naruishi K, Arai H, Nishimura F, Takashiba S. IL-6/sIL-6R enhances cathepsin B and L production via caveolin-1-mediated JNK-AP-1 pathway in human gingival fibroblasts. J Cell Physiol 2008; 217(2):423-32. https://doi.org/10.1002/jcp.21517

[18] Hoffmann M, Kleine-Weber H, Schroeder S, Krüger N, Herrler T, Erichsen S, et al. SARS-CoV-2 Cell entry depends on ACE2 and TMPRSS2 and is blocked by a clinically proven protease inhibitor. Cell 2020; 181(2):271-280.e8. https://doi.org/10.1016/j.cell.2020.02.052 